\title{
Antiviral drug discovery by targeting the SARS-CoV-2 polyprotein processing by inhibition of the main protease
}

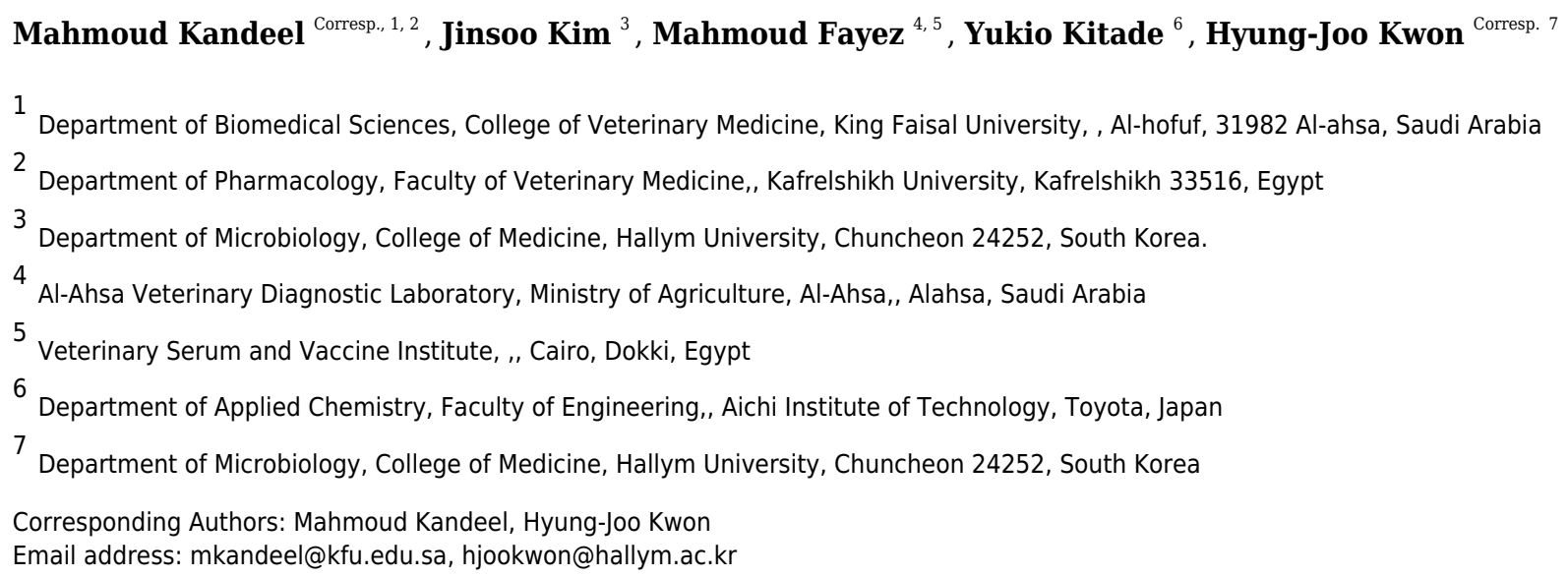

The spread of SARS CoV-2, the causative agent for COVID-19, has led to a global and deadly pandemic. To date, few drugs have been approved for treating SARS CoV-2 infections. In this study, a structure-based approach was adopted using the SARS CoV-2

main protease $\left(\mathrm{M}^{\text {pro }}\right)$ and a carefully selected dataset of 37060 compounds comprising $\mathrm{M}^{\text {pro }}$ and antiviral protein-specific libraries. The compounds passed two-step docking filtration, starting with standard precision (SP) followed by extra precision (XP) runs. Fourteen compounds with the highest XP docking scores were examined by 20 ns molecular dynamics simulations (MDs). Based on backbone route mean square deviations (RMSD) and molecular mechanics/generalized Born surface area (MM/GBSA) binding energy, four drugs were selected for comprehensive MDs analysis at $100 \mathrm{~ns}$. Results indicated that birinapant, atazanavir, and ritonavir potently bound and stabilized SARS CoV-2 Mpro structure. Binding energies higher than $-102 \mathrm{kcal} / \mathrm{mol}$, RMSD values $<0.22 \mathrm{~nm}$, formation of several hydrogen bonds with $\mathrm{M}^{\text {pro }}$, favourable electrostatic contributions, and low radii of gyration were among the estimated factors contributing to the strength of the binding of these three compounds with $\mathrm{M}^{\text {pro }}$. The top two compounds, atazanavir and birinapant, were tested for their ability to prevent SARS-CoV-2 plaque formation. At $10 \mu \mathrm{M}$ of birinapant concentration, antiviral tests against SARS-CoV-2 demonstrated a $37 \%$ reduction of virus multiplication. Antiviral assays demonstrated that birinapant has high anti-SARS-CoV-2 activity in the low micromolar range, with an IC50 value of $18 \pm 3.6 \mu \mathrm{M}$. Therefore, birinapant is a candidate for further investigation to determine whether it is a feasible 
therapy option. 


\section{Antiviral drug discovery by targeting the SARS-CoV-2 polyprotein}

\section{2 processing by inhibition of the main protease}

\section{Mahmoud Kandeel ${ }^{1,2, *}$, Jinsoo Kim³, Mahmoud Fayez ${ }^{4,5}$, Yukio Kitade ${ }^{6}$, Hyung-Joo Kwon $^{3 \text {,* }}$}

${ }^{1}$ Department of Biomedical Sciences, College of Veterinary Medicine, King Faisal University, Alhofuf, 31982 Al-ahsa, Saudi Arabia; ${ }^{2}$ Department of Pharmacology, Faculty of Veterinary Medicine, Kafrelshikh University, Kafrelshikh 33516, Egypt

${ }^{3}$ Department of Microbiology, Hallym University College of Medicine, Chuncheon 24252, South Korea.

${ }^{4}$ Al-Ahsa Veterinary Diagnostic Laboratory, Ministry of Agriculture, Al-Ahsa, Kingdom of Saudi Arabia

${ }^{5}$ Veterinary Serum and Vaccine Institute, Dokki, Cairo, Egypt

${ }^{6}$ Department of Applied Chemistry, Faculty of Engineering, Aichi Institute of Technology, 1247 Yachigusa, Yakusa-cho, Toyota, Aichi 470-0392, Japan.

*Correspondence to

Mahmoud Kandeel, Email: mkandeel@kfu.edu.sa

Hyung-Joo Kwon, Email hjookwon@,hallym.ac.kr 
20

21

22

\section{Abstract}

The spread of SARS CoV-2, the causative agent for COVID-19, has led to a global and deadly pandemic. To date, few drugs have been approved for treating SARS CoV-2 infections. In this study, a structure-based approach was adopted using the SARS CoV-2 main protease $\left(\mathrm{M}^{\mathrm{pro}}\right)$ and a carefully selected dataset of 37060 compounds comprising $\mathrm{M}^{\text {pro }}$ and antiviral protein-specific libraries. The compounds passed two-step docking filtration, starting with standard precision (SP) followed by extra precision (XP) runs. Fourteen compounds with the highest XP docking scores were examined by 20 ns molecular dynamics simulations (MDs). Based on backbone route mean square deviations (RMSD) and molecular mechanics/generalized Born surface area (MM/GBSA) binding energy, four drugs were selected for comprehensive MDs analysis at 100 ns. Results indicated that birinapant, atazanavir, and ritonavir potently bound and stabilized SARS CoV-2 $\mathrm{M}^{\mathrm{pro}}$ structure. Binding energies higher than $-102 \mathrm{kcal} / \mathrm{mol}$, RMSD values $<0.22 \mathrm{~nm}$, formation of several hydrogen bonds with $\mathrm{M}^{\text {pro }}$, favourable electrostatic contributions, and low radii of gyration were among the estimated factors contributing to the strength of the binding of these three compounds with $\mathrm{M}^{\mathrm{pro}}$. The top two compounds, atazanavir and birinapant, were tested for their ability to prevent SARS-CoV-2 plaque formation. At $10 \mu \mathrm{M}$ of birinapant concentration, antiviral tests against SARS-CoV-2 demonstrated a 37\% reduction of virus multiplication. Antiviral assays demonstrated that birinapant has high anti-SARS-CoV-2 activity in the low micromolar range, with an IC50 value of $18 \pm 3.6 \mu \mathrm{M}$. Therefore, birinapant is a candidate for further investigation to determine whether it is a feasible therapy option.

\section{Key words}

SARS-CoV-2; COVID-19; main protease; molecular modeling; drug discovery 


\section{Introduction}

The recent outbreak of SARS-CoV-2 has been declared a pandemic by WHO (Cucinotta \& Vanelli 2020). The disease COVID-19 causes a range of symptoms, from mild respiratory symptoms to severe respiratory distress associated with sepsis, multi-organ dysfunction, and death (Zaim et al. 2020). The current alarming situation necessitates the rapid reallocation or repurposing of previously known drugs or chemical compounds for the use in treating COVID-19.

Approximately seven human coronaviruses $(\mathrm{HCoV})$ have been identified. Four CoVs were identified as causative agents for mild respiratory symptoms and the common cold, including HCoV-229E, HCoV-NL63, HCoV-OC43, and HCoV-HKU1 (Zeng et al. 2018). However, more recently, severe symptoms and fatal outcomes have been caused by three other epidemic viruses, including SARS-CoV, MERS-CoV, and SARS-CoV-2. Coronaviruses express their nonstructural protein in the form of a large protein called polyprotein AB. This polyprotein has to be processed by the host as well as the viral encoded proteases to release approximately 16 NSPs. Two viral proteases share in the digestion of polyprotein AB: the main protease, called 3-C-like protease $\left(\mathrm{M}^{\text {pro }}\right)$, and a papain-like protease (PL ${ }^{\text {pro }}$ ) (Hilgenfeld 2014). Both PL ${ }^{\text {pro }}$ and $\mathrm{M}^{\text {pro }}$ have been important targets for drug discovery against SARS CoV, MERS CoV, and SARS CoV-2 (Kandeel et al. 2019; Li et al. 2019; Pillaiyar et al. 2020; Zumla et al. 2016).

The magic bullet for treating SARS-CoV2 is drug repurposing. As a result, numerous compounds were developed as anti-SARS-CoV-2 agents and therapies or prevent the virus's sequelae, have been studied in silico, in vitro, and in human clinical trials (Ghareeb et al. 2021). Several molecular targets were utilized to develop novel chemicals to combat Coronaviruses such as virus spike (Choudhary et al. 2021), main protease (Mostafa et al. 2021), papain-like protease (Delre et al. 2020; Mahmoud et al. 2021), helicase (Gurung 2020) and RNA-dependent RNA polymerase (Molavi et al. 2021).

In silico drug development investigations focused on the primary protease of SARS-CoV-2. The studies include docking and virtual screening of phytochemicals (Mandal et al. 2021), Hepatic C virus FDA approved drugs (Uddin et al. 2021), clinically approved and investigational drugs (Durdagi et al. 2021), nonsteroidal anti-inflammatory drugs (Abo Elmaaty et al. 2021) and antiallergic agents (Uras et al. 2021). A combination of in silico and in vitro drug repurposing against the SARS-CoV-2 main protease resulted in the identification of several hopeful 
peptidomimetics (Zhang et al. 2020) and small molecules as diclazuril (Pohl et al. 2021), nilotinib (Banerjee et al. 2021), ritonavir, rotigaptide, and cefotiam (Durdagi et al. 2021).

Recently, we provided computational details regarding targeting the $\mathrm{M}^{\text {pro }}$ and $\mathrm{PL}^{\text {pro }}$, wherein we used a dataset of FDA-approved drugs (Kandeel et al. 2020; Kandeel \& Al-Nazawi 2020). In this

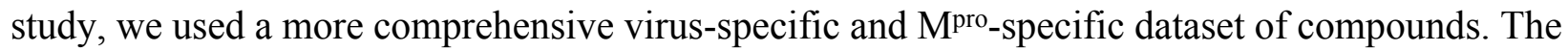
selected compounds in this study (Table 1) were selected from chemical libraries of millions of compounds. The compounds were approved by chemical screening compounds libraries providers with the specific aims of 1) conducting a ligand and structure-based search of HTS databases using $\mathrm{M}^{\text {pro }}$ specific features, 2) performing a 2D fingerprint similarity search against the biologically active compounds from therapeutically relevant viral assays, and 3) exploring specific viral protein binding compounds, antiviral nucleotides, and nucleotide mimetics agents. A total of 37060 compounds were retrieved and used in our virtual screening, docking, and molecular dynamics simulations. The results will help in the design and application of new compounds in treating COVID-19.

\section{Materials and methods}

\section{Construction of drugs and compounds dataset and ligand preparation}

A total of 37060 compounds dataset was constructed comprising SARS CoV-2 main protease targeted library, compounds obtained from 2D fingerprint from therapeutically relevant antiviral assays, combined ligand and structure-based approaches of inhibitors of viral proteins (Table 1). All compounds were prepared for virtual screening by Ligprep software using OPLS2005 force field (Supplementary files 1 and 2).

\section{SARS CoV-2 Mpro protein preparation}

The structure of Mpro (PDB ID 6lu7) was downloaded from the Protein Data Bank. The protein structure was processed and optimized using the Maestro software package's protein preparation wizard (Schrodinger LLC, NY, USA). The protein was protonated, the structure was optimized at cellular pH settings, and the structural energy was minimized using the OPLS2005 force field. The prepared structure was used in all docking and molecular dynamics calculations in this study.

\section{Virtual screening}


103 Docking of all compounds was performed by Schrodinger Glide docking module. Two-step 104 docking runs were carried out. Initially, the compounds were docked by the standard precision 105 docking protocol (SP docking). Compounds with docking scores of -8.00 or lower were retrieved 106 and subjected to extra precision (XP-docking). This score is suggested to be strong binding 107 compounds with shallow or hydrophobic cavities. The co-crystallized ligand served as the core of 108 a 20-size docking box that encircled the bound ligand in the creation of the docking grid. The 109 obtained results were ranked according to the obtained docking scores.

\section{Molecular dynamics (MD)simulations}

111 The MD simulations were carried out using GROMACS 5.1.4. (Abraham et al. 2015; Van Der 112 Spoel et al. 2005). The parameters and optimization of the simulation system were as previously 113 reported (Al-Hizab \& Kandeel 2021). Briefly, protein and ligands were handled by 114 AMBERFF14SB and AMBER force field (GAFF). The complexes were dissolved in a single point 115 charge water model in a cubic box of $1.0 \mathrm{~nm}$. For 5000 steps, the solvated Mro-ligand complexes 116 were minimized. At $300 \mathrm{~K}$, the entire system was equilibrated in two phases: NVT ensemble of 50 117 ps, followed by NPT ensemble for $1 \mathrm{~ns}$. For all compounds, the production stages were extended 118 to $20 \mathrm{~ns}$. The simulations of the top four compounds were then extended to $100 \mathrm{~ns}$. The pressure 119 and temperature contrls were by Parrinello-Rahman algorithm and V-rescale thermostat algorithm, 120 respectiely. For long-range electrostatics, the Particle Mesh Ewald (PME) technique was utilized 121 (12 $\AA$ direct space cut-off). A two fs was chosen as the time step. The output data were 122 collected every $10 \mathrm{ps}$. In the trajectory analysis, GROMACS MD simulation toolkits were used. 123 The root mean square deviation (RMSD) and per-residue root mean square fluctuation (RMSF) of 124 protein residues were calculated using the $\mathrm{g}$ rms and $\mathrm{g}$ rmsf functions, respectively. The binding energy was calculated using the g mmpbsa tool (Kumari et al. 2014).

SARS-CoV-2 plaques inhibition assay

\section{Cell line and virus}

128 African green monkey kidney Vero E6 cells were purchased from the Korean Cell Line Bank 129 (Seoul, Korea). The incubation and handling of cells was as previously described (Kandeel et al. 130 2021). The Korean Cell Line Bank authenticated Vero E6 cells with tests for morphology, growth 131 pattern, histopathology, DNA fingerprinting, and mycoplasma contamination. We also checked 
132 the mycoplasma contamination using mycoplasma PCR detection kit (Myco-sniff ${ }^{\mathrm{TM}}$ mycoplasma

133 PCR detection kit, MP Biomedicals, Irvine, CA, USA). We prepared stocks for the cell line at 134 early passages, and the cell line was maintained until passage 20 (within 2 months) and then 135 discarded. SARS-CoV-2 S clade (hCoV-19/South Korea/KCDC03/2020, EPI_ISL_407193) was 136 provided by the National Culture Collection for Pathogens (Osong, Korea).

137

138

Virus amplification and virus quantification by plaque assay

139 Vero E6 cells $\left(5 \times 10^{4}\right.$ cells/well 6 -well plates $)$ were cultured overnight. The cells were infected 140 with SARS-CoV-2 in PBS (0.1 MOI) for $1 \mathrm{~h}$ in a $\mathrm{CO}_{2}$ incubator at $37^{\circ} \mathrm{C}$, then $2 \mathrm{ml}$ of DMEM 141 containing 2\% FBS was added. After $3 \mathrm{~h}$ incubation in a $\mathrm{CO}_{2}$ incubator at $37^{\circ} \mathrm{C}$, the cells were 142 treated with DMSO $(0.1 \%)$, birinapant $(10 \mu \mathrm{M})$ or atazanavir $(10 \mu \mathrm{M})$ and incubated for $48 \mathrm{~h}$. 143 The virus replication was evaluated using the plaque formation assay. SARS-CoV-2 experiments 144 were approved by the Institutional Biosafety Committee of Hallym University (Permit no. 145 Hallym2020-12) and The amplification of SARS-CoV-2 and the experimental techniques were 146 carried out under a biosafety level 3 (BSL-3) environment.

\section{Statistical analysis}

148 Correlation statistics were carried out by GraphPad Prism software. The Pearson's correlation coefficient was used to conclude the significance of the results.

\section{Results}

\section{Virtual screening and docking}

153 Recently, we used molecular modeling, virtual screening, and MD) simulation in characterization of the biological aspects of microbial agents, characterization of diseases, and drug discovery (Altaher \& Kandeel 2016; Altaher et al. 2015; Sheikh et al. 2020). This study used an antiviral and $\mathrm{M}^{\text {pro }}$-specific dataset. Virtual screening and docking comprised a two-step process. First, an initial standard-precision (SP) docking protocol was performed, with compounds having a docking score of -8.00 or higher (453 compounds) selected for extra-precision (XP) evaluation. Supplementary file 1 contains the docked compounds ordered by docking score. After SP-docking, the selected 
161 of which are provided in Supplementary file 2. The top 14 compounds with the highest docking 162 scores were used in MD simulations, taking lopinavir as a reference inhibitor (Table 2). All of the 163 top compounds showed favourable profiles and negative scores for Hbond, hydrophobic 164 interactions, vdw, and coulombic interactions. Likewise, the calculated binding energy scores 165 (MM-GBSA) were favourable and indicated strong binding profiles, with values ranging from 16656.67 to $-106.64 \mathrm{kcal} / \mathrm{mol}$ (Table 1$)$.

167 Statistical analysis comprised determining the correlation between the obtained docking score and 168 ligand efficiency, lipo, Hbond, vdw, coulombic, Glide energy, and binding energy scores (Table 169 3). A strong negative correlation was observed between docking score and lipophilic interactions $170(\mathrm{r}=-0.60, p>0.05)$, and a positive correlation with columbic interactions $(\mathrm{r}=0.74, p>0.05)$. This 171 implies a predominance of electrostatic interactions in compounds binding with SARS CoV-2 $172 \mathrm{M}^{\text {pro. }}$.

173 The determined binding features for each compound with Mpro are provided in Fig. 1. The binding 174 site is mostly composed of hydrophobic residues (THR24, THR25, LEU27, VAL42, MET49, 175 PRO52, TYR54, PHE140, LEU141, MET165, LEU167, and THR190); also present are few 176 positively charged residues (ARG188), negatively charged residues (GLU166 and ASP187), and neutral residues (CYS44, SER144, GLN189, and GLN192).

\section{Molecular dynamics simulations for $20 \mathrm{~ns}$}

180

181

182

183

184

185

186

187

188

189

A potent drug discovery tool is the combination of docking and MD modelling. Drugs can be graded based on their binding affinity and precise interaction with ligand-receptor intermediates using these methods. MD simulation and post-dynamic binding energy analysis were performed on the top-ranked compounds from XP-docking. Two stages of compound filtering were used. The RMSD, RMSF, and binding energy values of all 14 compounds were calculated after they were simulated in MD for $20 \mathrm{~ns}$. The top four compounds were studied in a more extensive $100 \mathrm{~ns}$ simulation in the second stage. The structural changes in $\mathrm{M}^{\text {pro }}$ backbone residues were compared (Fig. 2). All treatment complexes, with the exception of Apo $\mathrm{M}^{\text {pro }}$ and $\mathrm{M}^{\text {pro }}$ combined with cobicistat and glycitin, showed high stability.

\section{MM-GBSA binding energies}


190 The MM-GBSA binding energies of the 14 compounds ranged from $-42.627 \mathrm{kcal} / \mathrm{mol}$ to -42.627

$191 \mathrm{kcal} / \mathrm{mol}$. The top six compounds showed MM-GBSA binding energies ranging from -102.564 to $192-139.154$, indicating a likely substantial binding affinity. Furthermore, all of the investigated 193 compounds had low structural RMSD throughout the 20 ns simulations, with RMSD values as low 194 as $0.21 \mathrm{~nm}$ (Table 4).

\section{Molecular dynamics simulations for $100 \mathrm{~ns}$}

197

198

199

200

201

202

203

204

205

206

207

208

209

210

211

212

213

214

215

216

217

To gain a better understanding of the strongest-binding drugs, the four drugs with binding energies greater than $-100 \mathrm{kcal} / \mathrm{mol}$ (alpha-mangostin, atazanavir, birinapant, and lopinavir) were subjected to 100 ns MD simulations, followed by analyses of RMSD, RMSF, hbond length, and Rg and binding energy. All four had promising binding free energy values (Table 4). Specifically, the estimated MM-GBSA binding energy values were $-117.90,-117.83,-121.80$, and -112.80 for alpha-mangostin, atazanavir, birinapant, and lopinavir, respectively. The three drugs alphamangostin, atazanavir, and birinapant are implied by these values to have superior binding over lopinavir.

After $100 \mathrm{~ns}$ MDs, average RMSD values of $0.23,0.20,0.21$, and $0.18 \mathrm{~nm}$ were obtained for alphamangostin, atazanavir, birinapant, and lopinavir, respectively. Relative to experimental RMSD ranges, these values indicate marked stability of all four drugs when complexed with Mpro. Such complexes can be ranked in terms of stability as follows: lopinavir $>$ atazanavir $>$ birinapant $>$ alphamangostin. The low ranking of alpha-mangostin can be explained by the abrupt drift in its RMSD value at $22 \mathrm{~nm}$, observable in Fig. 3. The energy value obtained for alpha-mangostin likewise indicates a lower affinity to $M^{\text {pro }}$. Meanwhile, the per-residue RMSF (Fig. 4) shows conserved RMSF features in $\mathrm{M}^{\text {pro }}$ complexes with lopinavir, birinapant, and atazanavir. Surprisingly, alphamangostin showed several protein fragments with very high RMSD values of $0.4 \mathrm{~nm}$. Nonetheless, based on observations of binding energy, RMSD, and RMSF values, we can exclude alphamangostin from being repurposed on the basis of interaction with SARS CoV-2 Mpro.

\section{Radius of gyration}


218 The radius of gyration can be used to determine the compactness of a system, with lower Rg values

219 indicating more stable structures and higher $\mathrm{Rg}$ values indicating less compactness or more 220 unfolded protein. All four top drugs had an average $\mathrm{Rg}$ value of $2.21 \mathrm{~nm}$; these similar Rg values

221 indicate the stability of the examined drugs when complexed with Mpro. Fig. 5 shows the variation

222 in Rg obtained during 100 ns MD simulations. Birinapant and ritonavir showed almost similar

223 profiles with less-variable Rg, while alpha-mangostin and atazanavir showed biphasic profiles of

224 alternating higher and lower $\mathrm{Rg}$. Nonetheless, the overall average $\mathrm{Rg}$ values were similar for the

225 four drugs.

226

227

228

229

230

231

232

233

234

235

236

237

238

239

240

241

242

243

244

245

\section{Hydrogen bond length}

Figure 6 shows the average hydrogen bond length obtained using GLU166 over a 100 ns simulation. Birinapant, with an average length of $0.25 \mathrm{~nm}$, demonstrated the only stable binding with GLU166.

\section{Decomposition of MM-GBSA binding energy}

The primary interactions during drug recognition by $\mathrm{M}^{\text {pro }}$ were studied using post-dynamic energy decomposition analysis (Table 5). The findings revealed that vdw and electrostatic interactions were the most critical forces for all four drugs. More specifically, vdw was the major force for alpha-mangostin, atazanavir, and lopinavir, while electrostatic forces were the major contributor for birinapant binding, with a lesser contribution from vdw.

\section{SARS-CoV-2 Plaque inhibition assay}

Plaques inhibition assays in Vero E6 cells were used to explore the drug inhibitory properties against SARS-CoV-2 infection. At a concentration of $10 \mu \mathrm{M}$, atazanavir had no antiviral effects. Birinapant, on the other hand, reduced the production of SARS-CoV-2 plaques by 37\% (Fig. 7). Treatment with birinapant significantly inhibited the SARS-CoV-2 plaque formation in a dosedependent manner. The estimated $\mathrm{IC}_{50}$ values for birinapant was $18 \pm 3.6 \mu \mathrm{M}$.

\section{Discussion}


246 With the emergence of SARS-CoV-2 in December 2019 and its rapid worldwide spread, drug 247 repurposing has been one tool available to combat the disease. Many drugs with proven efficiency 248 and safety have been repurposed for other clinical applications. Sildenafil is one such drug; it was 249 initially produced to treat angina and later used for male erectile dysfunction (Goldstein et al. 250 1998); zidovudine was repurposed earlier from an anticancer drug to an anti-HIV agent (Ashburn $251 \&$ Thor 2004), and the antidepressant dapoxetine has been effective in managing premature 252 ejaculation (Fu et al. 2019).

253 The SARS-CoV-2 Mro has been an attractive target in many drug discovery studies. The M ${ }^{\text {pro }}$ was 254 targeted by a number of compound libraries, including those containing drugs approved by the 255 Food and Drug Administration (Kandeel \& Al-Nazawi 2020), flavonoids and natural compounds 256 (Joshi et al. 2020; Vijayakumar et al. 2020), tetracycline (Bharadwaj et al. 2020) and microbial 257 natural products (Sayed et al. 2020). In this study, a large library of virus protein-specific 258 compounds was selected. Initial docking showed interesting docking scores and favourable 259 profiles of structure stability and binding energy. The four drugs selected for the final 260 comprehensive $100 \mathrm{~ns}$ MD) simulations were alpha-mangostin, atazanavir, birinapant and 261 lopinavir.

262 Lopinavir is a well-known protease inhibitor with high efficiency against the HIV-1 protease 263 (Cvetkovic \& Goa 2003). In addition, the drug was effective against SARS-CoV and MERS-CoV 264 (Chan et al. 2015) and improved the health markers in SARS-CoV-2-infected patients (Ye et al. 2020). Atazanavir is another HIV-1 protease inhibitor with the advantage of oral administration in

266

267

268

269

270

271

272

273

274 combination with other antiretroviral drugs (Goldsmith \& Perry 2003). Birinapant is an apoptosis inhibitor, and it has approved efficiency in controlling viral hepatitis in combination with other antiviral drugs (Testoni et al. 2017). Previous in silico research showed that birinapant could bind to the main protease of the SARS-CoV-2 virus (Lokhande et al. 2021). In our study, in comparison with lopinavir, both atazanavir and birinapant showed an improved XP-docking score, higher binding energy and a lower structural root-mean-square deviation (RMSD) during 100 ns MD simulations. Therefore, based on the clinical efficiency of lopinavir against SARS-CoV-2, the drugs atazanavir and birinapant are expected to perform with similar or improved efficacy comparable to that of ritonavir. Interestingly, it was recently shown that atazanavir can inhibit Mpro 
275 activity while simultaneously suppressing SARS-CoV-2 replication (Fintelman-Rodrigues et al. 276 2020).

277 The strong binding profiles of atazanavir and birinapant are supported with hydrophobic 278 interactions. In addition, atazanavir formed two hydrogen bonds with ASN142 and GLU166, and 279 birinapant formed four hydrogen bonds with THR25, GLU166, and GLN192 and a tridentate bond 280 with GLY143, SER144 and CYS145 (Figure 1E and F).

281 In the second rank, following atazanavir and birinapant, alpha-mangostin and cobicistat showed 282 quite high binding energy but had less structural stability owing to higher RMSD values. Cobicistat 283 is a cytochrome enzyme inhibitor used to increase the systemic availability of other antiviral drugs, 284 such as atazanavir (Xu et al. 2010).

285 After screening investigations, the top two compounds were used in antiviral assays. Atazanavir 286 had no antiviral effects. Atazanavir has been shown to have anti-SARS-CoV-2 action in previous 287 studies (Fintelman-Rodrigues et al. 2020). The lack of antiviral effectiveness of atazanavir found 288 in our investigation might indicate that slight differences in the type of virus utilised could alter 289 atazanavir efficacy. In contrast, birinapant has antiviral properties at low micromolar 290 concentrations. The measured EC50 value of birinapant $(18 \mu \mathrm{M})$ coincides with the measured 291 value for other known antiviral drugs such as remdesivir and lopinavir, which yielded EC50 values 292 against SARS-CoV-2 replication at 23.15 and $26.63 \mu \mathrm{M}$, respectively (Choy et al. 2020). 293 Birinapant's anti-SARS-CoV-2 activity supports further investigation into its usage as an anti294 COVID-19 medication. Combining birinapant with other antivirals may result in considerable 295 SARS-CoV-2 virus particle elimination.

\section{Conclusion}

297 After a comprehensive study involving virtual screening, docking, and MD simulations of a unique

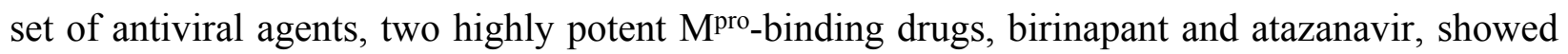
promise. These drugs had improved energetic and structural stability profiles that were comparable to or higher than those produced by the classic antiviral protease inhibitor ritonavir. Birinapant was found to inhibit SARS-CoV-2 replication with promising inhibition in the low micromolar range. 
304 Supplementary Materials: All data are within the manuscript and the supplementary materials.

305 Author Contributions: "Conceptualization, M.K., J.K., M.F. and H.K.; methodology, M.K. and J.K.; software, M.K.; validation, M.K., J.K., M.F. and H.K, formal analysis, M.K., J.K., M.F. and H.K.; investigation, M.K., J.K., M.F. and H.K; resources, M.K. and H.K; data curation, H.K.; writing — original draft preparation, M.K.; writing—review and editing, H.K.; funding acquisition, M.K. All authors have read and agreed to the published version of the manuscript.

Funding: This project is funded by the Ministry of Health, Saudi Arabia, Project number (495) and date 11/9/1441H. The authors acknowledge King Faisal University for providing support, facilities and labs.

Acknowledgments: This project is funded by the Ministry of Health, Saudi Arabia, Project number (495) and date 11/9/1441H. The authors acknowledge King Faisal University for providing support, facilities and labs.

Conflicts of Interest: MK received financial support from the ministry of health, Saudi Arabia for searching new binding drugs with SARS CoV-2 main protease. The funding agent has no role in data curation and analysis and results. The authors declare no conflict of interest.

\section{References}

Abo Elmaaty A, Hamed MIA, Ismail MI, E BE, H SA, Khattab M, and Al-Karmalawy AA. 2021. Computational Insights on the Potential of Some NSAIDs for Treating COVID-19: Priority Set and Lead Optimization. Molecules 26. 10.3390/molecules26123772

Abraham MJ, Murtola T, Schulz R, Páll S, Smith JC, Hess B, and Lindahl E. 2015. GROMACS: High performance molecular simulations through multi-level parallelism from laptops to supercomputers. SoftwareX 1:19-25.

Al-Hizab F, and Kandeel M. 2021. Mycophenolate suppresses inflammation by inhibiting prostaglandin synthases: a study of molecular and experimental drug repurposing. PeerJ 9:e11360.

Altaher Y, and Kandeel M. 2016. Molecular analysis of some camel cytochrome P450 enzymes reveals lower evolution and drug-binding properties. Journal of Biomolecular Structure and Dynamics 34:115-124.

Altaher Y, Nakanishi M, and Kandeel M. 2015. Annotation of Camel Genome for Estimation of Drug Binding Power, Evolution and Adaption of Cytochrome P450 1a2. International Journal of Pharmacology 11:243-247.

Ashburn TT, and Thor KB. 2004. Drug repositioning: identifying and developing new uses for existing drugs. Nat Rev Drug Discov 3:673-683. 10.1038/nrd1468 
337

Banerjee S, Yadav S, Banerjee S, Fakayode SO, Parvathareddy J, Reichard W, Surendranathan S, Mahmud F, Whatcott R, Thammathong J, Meibohm B, Miller DD, Jonsson CB, and Dubey KD. 2021. Drug Repurposing to Identify Nilotinib as a Potential SARS-CoV-2 Main Protease Inhibitor: Insights from a Computational and In Vitro Study. J Chem Inf Model 61:5469-5483. 10.1021/acs.jcim.1c00524

Bharadwaj S, Lee KE, Dwivedi VD, and Kang SG. 2020. Computational insights into tetracyclines as inhibitors against SARS-CoV-2 M(pro) via combinatorial molecular simulation calculations. Life Sci 257:118080. 10.1016/j.Ifs.2020.118080

Chan JF-W, Yao Y, Yeung M-L, Deng W, Bao L, Jia L, Li F, Xiao C, Gao H, and Yu P. 2015. Treatment with lopinavir/ritonavir or interferon- $\beta 1 \mathrm{~b}$ improves outcome of MERS-CoV infection in a nonhuman primate model of common marmoset. The Journal of infectious diseases 212:1904-1913.

Choudhary V, Gupta A, Sharma R, and Parmar HS. 2021. Therapeutically effective covalent spike protein inhibitors in treatment of SARS-CoV-2. J Proteins Proteom:1-14. 10.1007/s42485-021-00074-X

Choy KT, Wong AY, Kaewpreedee P, Sia SF, Chen D, Hui KPY, Chu DKW, Chan MCW, Cheung PP, Huang X, Peiris M, and Yen HL. 2020. Remdesivir, lopinavir, emetine, and homoharringtonine inhibit SARSCoV-2 replication in vitro. Antiviral Res 178:104786. 10.1016/j.antiviral.2020.104786

Cucinotta D, and Vanelli M. 2020. WHO declares COVID-19 a pandemic. Acta bio-medica: Atenei Parmensis 91:157-160.

Cvetkovic RS, and Goa KL. 2003. Lopinavir/ritonavir. Drugs 63:769-802.

Delre P, Caporuscio F, Saviano M, and Mangiatordi GF. 2020. Repurposing Known Drugs as Covalent and Non-covalent Inhibitors of the SARS-CoV-2 Papain-Like Protease. Front Chem 8:594009. 10.3389/fchem.2020.594009

Durdagi S, Orhan MD, Aksoydan B, Calis S, Dogan B, Sahin K, Shahraki A, lyison NB, and Avsar T. 2021. Screening of Clinically Approved and Investigation Drugs as Potential Inhibitors of SARS-CoV-2: A Combined in silico and in vitro Study. Mol Inform:e2100062. 10.1002/minf.202100062

Fintelman-Rodrigues N, Sacramento CQ, Ribeiro Lima C, Souza da Silva F, Ferreira AC, Mattos M, de Freitas CS, Cardoso Soares V, da Silva Gomes Dias S, Temerozo JR, Miranda MD, Matos AR, Bozza FA, Carels N, Alves CR, Siqueira MM, Bozza PT, and Souza TML. 2020. Atazanavir, Alone or in Combination with Ritonavir, Inhibits SARS-CoV-2 Replication and Proinflammatory Cytokine Production. Antimicrob Agents Chemother 64. 10.1128/aac.00825-20

Fu M, Peng X, and Hu Y. 2019. Effect of premature ejaculation desensitisation therapy combined with dapoxetine hydrochloride on the treatment of primary premature ejaculation. Andrologia 51:e13135. 10.1111/and.13135

Ghareeb DA, Saleh SR, Nofal MS, Kaddah MMY, Hassan SF, Seif IK, El-Zahaby SA, Khedr SM, Kenawy MY, Masoud AA, Soudi SA, Sobhy AA, Sery JG, El-Wahab MGA, Elmoneam AAA, Al-Mahallawi AM, and El-Demellawy MA. 2021. Potential therapeutic and pharmacological strategies for SARSCoV2. Journal of pharmaceutical investigation:1-16. 10.1007/s40005-021-00520-4

Goldsmith DR, and Perry CM. 2003. Atazanavir. Drugs 63:1679-1693.

Goldstein I, Lue TF, Padma-Nathan H, Rosen RC, Steers WD, and Wicker PA. 1998. Oral sildenafil in the treatment of erectile dysfunction. New England Journal of Medicine 338:1397-1404.

Gurung AB. 2020. In silico structure modelling of SARS-CoV-2 Nsp13 helicase and Nsp14 and repurposing of FDA approved antiviral drugs as dual inhibitors. Gene Rep 21:100860. 10.1016/j.genrep.2020.100860

Hilgenfeld R. 2014. From SARS to MERS: crystallographic studies on coronaviral proteases enable antiviral drug design. The FEBS journal 281:4085-4096.

Joshi T, Joshi T, Pundir H, Sharma P, Mathpal S, and Chandra S. 2020. Predictive modeling by deep learning, virtual screening and molecular dynamics study of natural compounds against SARSCoV-2 main protease. J Biomol Struct Dyn:1-19. 10.1080/07391102.2020.1802341 
402

403

404

405

406

407

408

409

410

411

412

413

414

415

416

417

418

419

420

421

422

423

424

425

426

427

428

429

430

431

Kandeel M, Abdelrahman AH, Oh-Hashi K, Ibrahim A, Venugopala KN, Morsy MA, and Ibrahim MA. 2020. Repurposing of FDA-approved antivirals, antibiotics, anthelmintics, antioxidants, and cell protectives against SARS-CoV-2 papain-like protease. Journal of Biomolecular Structure and Dynamics:1-8.

Kandeel M, and Al-Nazawi M. 2020. Virtual screening and repurposing of FDA approved drugs against COVID-19 main protease. Life sciences:117627.

Kandeel M, Altaher A, and Alnazawi M. 2019. Molecular Dynamics and Inhibition of MERS CoV Papainlike Protease by Small Molecule Imidazole and Aminopurine Derivatives. Letters in Drug Design \& Discovery 16:584-591.

Kandeel M, Yamamoto M, Park BK, Al-Taher A, Watanabe A, Gohda J, Kawaguchi Y, Oh-Hashi K, Kwon H$\mathrm{J}$, and Inoue J-i. 2021. Discovery of New Potent anti-MERS CoV Fusion Inhibitors. Frontiers in Pharmacology 12:1241.

Kumari R, Kumar R, Consortium OSDD, and Lynn A. 2014. g_mmpbsa? A GROMACS tool for highthroughput MM-PBSA calculations. Journal of chemical information and modeling 54:1951-1962.

Li Y-H, Hu C-Y, Wu N-P, Yao H-P, and Li L-J. 2019. Molecular Characteristics, Functions, and Related Pathogenicity of MERS-CoV Proteins. Engineering.

Lokhande KB, Doiphode S, Vyas R, and Swamy KV. 2021. Molecular docking and simulation studies on SARS-CoV-2 M(pro) reveals Mitoxantrone, Leucovorin, Birinapant, and Dynasore as potent drugs against COVID-19. J Biomol Struct Dyn 39:7294-7305. 10.1080/07391102.2020.1805019

Mahmoud K, Byoung Kwon P, Mohamed AM, Katharigatta NV, Kentaro O-h, Mohammed A-N, and Hyung-Joo K. 2021. Virtual Screening and Inhibition of Middle East Respiratory Syndrome Coronavirus Replication by Targeting Papain-like Protease. Dr Sulaiman Al Habib Medical Journal. https://doi.org/10.2991/dsahmj.k.210921.001

Mandal A, Jha AK, and Hazra B. 2021. Plant Products as Inhibitors of Coronavirus 3CL Protease. Frontiers in Pharmacology 12:583387-583387. 10.3389/fphar.2021.583387

Molavi Z, Razi S, Mirmotalebisohi SA, Adibi A, Sameni M, Karami F, Niazi V, Niknam Z, Aliashrafi M, Taheri M, Ghafouri-Fard S, Jeibouei S, Mahdian S, Zali H, Ranjbar MM, and Yazdani M. 2021. Identification of FDA approved drugs against SARS-CoV-2 RNA dependent RNA polymerase (RdRp) and 3-chymotrypsin-like protease (3CLpro), drug repurposing approach. Biomed Pharmacother 138:111544. 10.1016/j.biopha.2021.111544

Mostafa I, Mohamed NH, Mohamed B, Almeer R, Abulmeaty MMA, Bungau SG, El-Shazly AM, and Yahya G. 2021. In-silico screening of naturally derived phytochemicals against SARS-CoV Main protease. Environ Sci Pollut Res Int:1-17. 10.1007/s11356-021-17642-9

Pillaiyar T, Meenakshisundaram S, and Manickam M. 2020. Recent discovery and development of inhibitors targeting coronaviruses. Drug Discovery Today.

Pohl MO, Busnadiego I, Marrafino F, Wiedmer L, Hunziker A, Fernbach S, Glas I, Moroz-Omori EV, Hale BG, Caflisch A, and Stertz S. 2021. Combined computational and cellular screening identifies synergistic inhibition of SARS-CoV-2 by lenvatinib and remdesivir. J Gen Virol 102. 10.1099/jgv.0.001625

Sayed AM, Alhadrami HA, El-Gendy AO, Shamikh YI, Belbahri L, Hassan HM, Abdelmohsen UR, and Rateb ME. 2020. Microbial Natural Products as Potential Inhibitors of SARS-CoV-2 Main Protease (M(pro)). Microorganisms 8. 10.3390/microorganisms8070970

Sheikh A, Al-Taher A, Al-Nazawi M, Al-Mubarak Al, and Kandeel M. 2020. Analysis of preferred codon usage in the coronavirus $\mathrm{N}$ genes and their implications for genome evolution and vaccine design. Journal of Virological Methods 277:113806.

Testoni B, Durantel D, and Zoulim F. 2017. Novel targets for hepatitis B virus therapy. Liver International 37:33-39. 
432

433

434

435

436

437

438

439

440

441

442

443

444

445

446

447

448

449

450

451

452

453

454

455

456

457

458

459

460

461

462

463
Uddin R, Jalal K, Khan K, and UI-Haq Z. 2021. Re-Purposing of Hepatitis C Virus FDA Approved Direct Acting Antivirals as Potential SARS-CoV-2 Protease Inhibitors. J Mol Struct:131920. 10.1016/j.molstruc.2021.131920

Uras IS, Ebada SS, Korinek M, Albohy A, Abdulrazik BS, Wang YH, Chen BH, Horng JT, Lin W, Hwang TL, and Konuklugil B. 2021. Anti-Inflammatory, Antiallergic, and COVID-19 Main Protease (M(pro)) Inhibitory Activities of Butenolides from a Marine-Derived Fungus Aspergillus terreus. Molecules 26. 10.3390/molecules26113354

Van Der Spoel D, Lindahl E, Hess B, Groenhof G, Mark AE, and Berendsen HJ. 2005. GROMACS: fast, flexible, and free. Journal of computational chemistry 26:1701-1718.

Vijayakumar BG, Ramesh D, Joji A, Jayachandra Prakasan J, and Kannan T. 2020. In silico pharmacokinetic and molecular docking studies of natural flavonoids and synthetic indole chalcones against essential proteins of SARS-CoV-2. Eur J Pharmacol 886:173448. 10.1016/j.ejphar.2020.173448

Xu L, Liu H, Murray BP, Callebaut C, Lee MS, Hong A, Strickley RG, Tsai LK, Stray KM, and Wang Y. 2010. Cobicistat (GS-9350): a potent and selective inhibitor of human CYP3A as a novel pharmacoenhancer. ACS medicinal chemistry letters 1:209-213.

Ye X, Luo Y, Xia S, Sun Q, Ding J, Zhou Y, Chen W, Wang X, Zhang W, and Du W. 2020. Clinical efficacy of lopinavir/ritonavir in the treatment of Coronavirus disease 2019. Eur Rev Med Pharmacol Sci 24:3390-3396.

Zaim S, Chong JH, Sankaranarayanan V, and Harky A. 2020. COVID-19 and multi-organ response. Current Problems in Cardiology:100618.

Zeng Z-Q, Chen D-H, Tan W-P, Qiu S-Y, Xu D, Liang H-X, Chen M-X, Li X, Lin Z-S, and Liu W-K. 2018. Epidemiology and clinical characteristics of human coronaviruses OC43, 229E, NL63, and HKU1: a study of hospitalized children with acute respiratory tract infection in Guangzhou, China. European Journal of Clinical Microbiology \& Infectious Diseases 37:363-369.

Zhang L, Lin D, Kusov Y, Nian Y, Ma Q, Wang J, von Brunn A, Leyssen P, Lanko K, Neyts J, de Wilde A, Snijder EJ, Liu H, and Hilgenfeld R. 2020. $\alpha$-Ketoamides as Broad-Spectrum Inhibitors of Coronavirus and Enterovirus Replication: Structure-Based Design, Synthesis, and Activity Assessment. J Med Chem 63:4562-4578. 10.1021/acs.jmedchem.9b01828

Zumla A, Chan JF, Azhar El, Hui DS, and Yuen K-Y. 2016. Coronaviruses-drug discovery and therapeutic options. Nature reviews Drug discovery 15:327. 


\section{Figure 1}

The docking site and ligands interactions with $\mathrm{M}^{\text {pro }}$.
A) The docking site of $\mathrm{M}^{\text {pro }}$ following XP docking protocol. B) Surface representation (blue) of birinapant in the active site of $\mathrm{M}^{\mathrm{pro}} \mathrm{C}$ ) The binding site of residues of atazanavir $\mathrm{D}$ ) The binding site residues of birinapant E) The ligand interactions of atazanavir F) The ligand interactions of birinapant. Hydrogen bonds are shown in purple arrows, hydrophobic interactions in grey circles. 

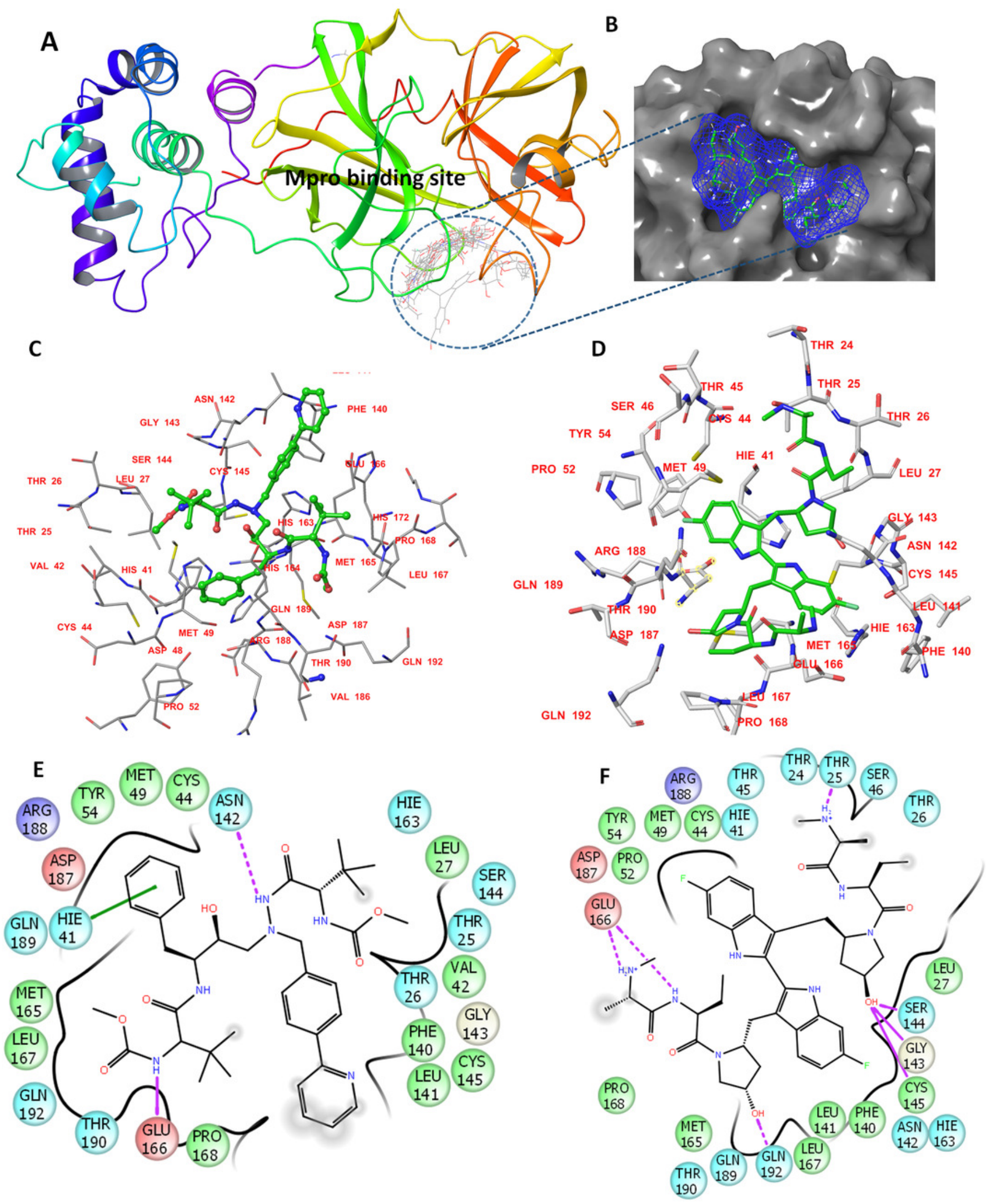
Figure 2

RMSD plot of the top fourteen compounds after MDS for 20 ns.

Lopinavir was used for reference. Apo structure is $\mathrm{M}^{\text {pro }}$ without any ligands. 


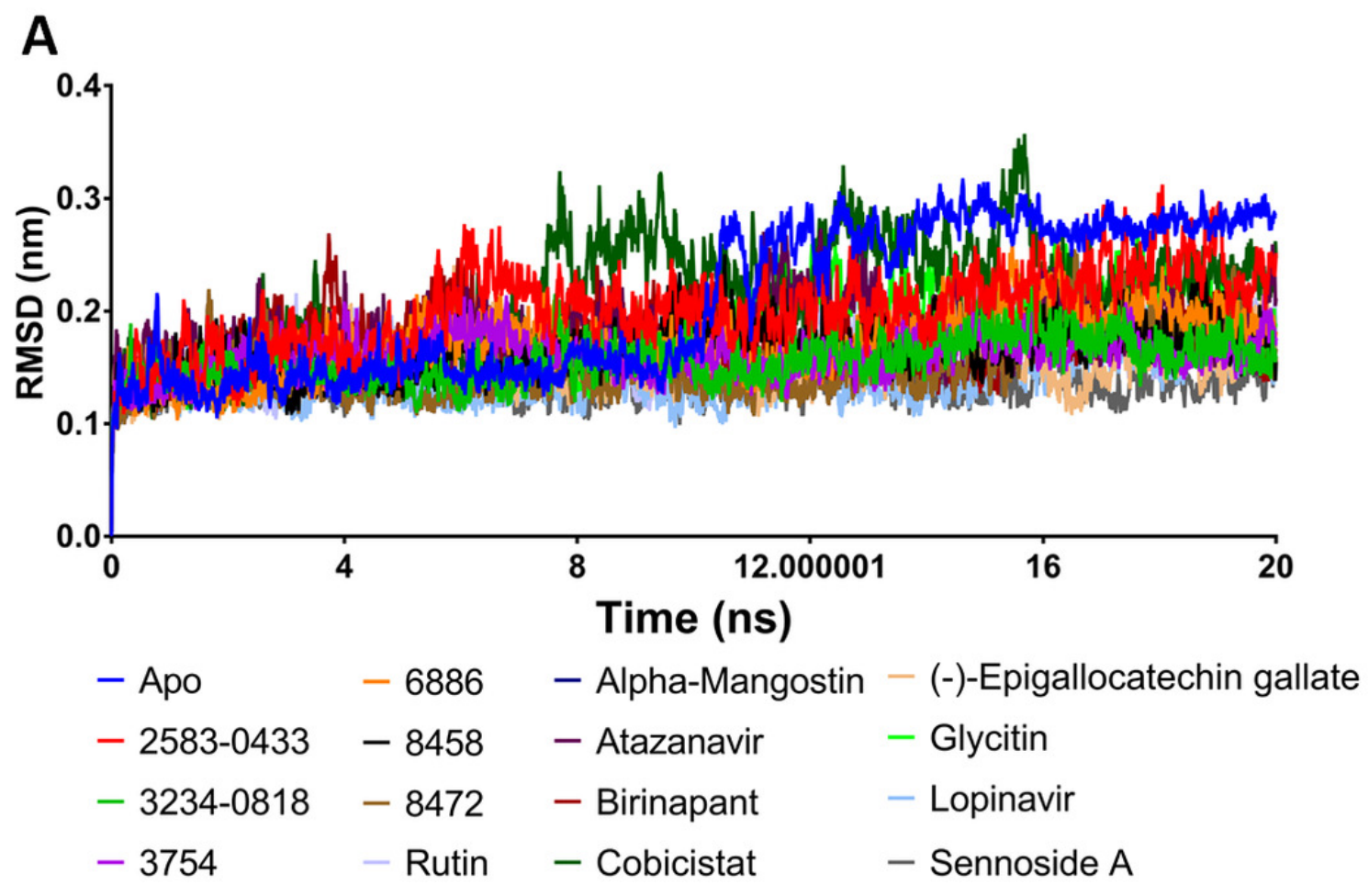

B

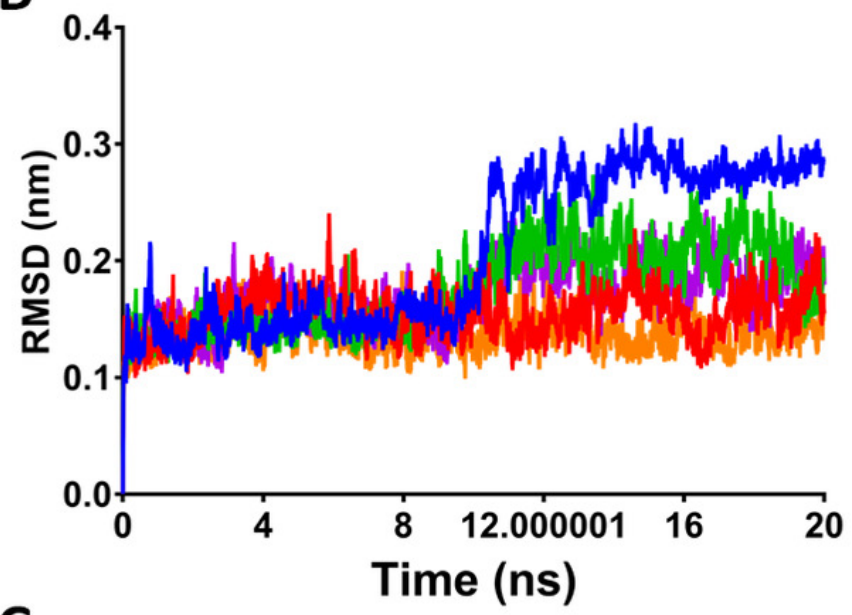

- Apo

- (-)-Epigallocatechin gallate

- Glycitin

- Rutin

- Sennoside A

C

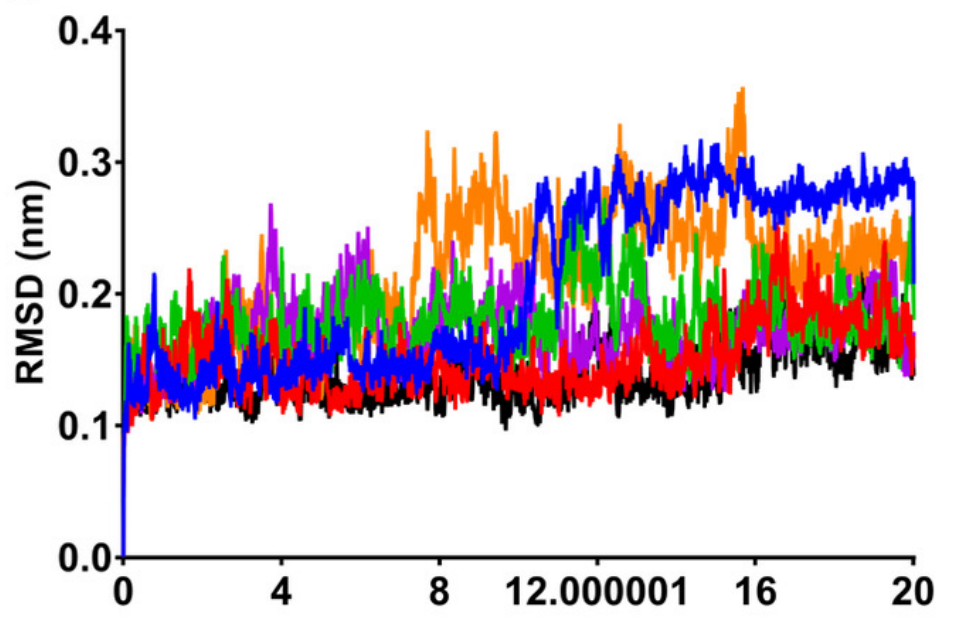

- Apo

- Alpha-Mangostin

- Atazanavir

- Birinapant

- Cobicistat

- Lopinavir 
Figure 3

RMSD plot of the top four compounds, alpha-mangostin, atazanavir, birinapant and lopinavir, after MDs for 100 ns.

\section{Lopinavir}

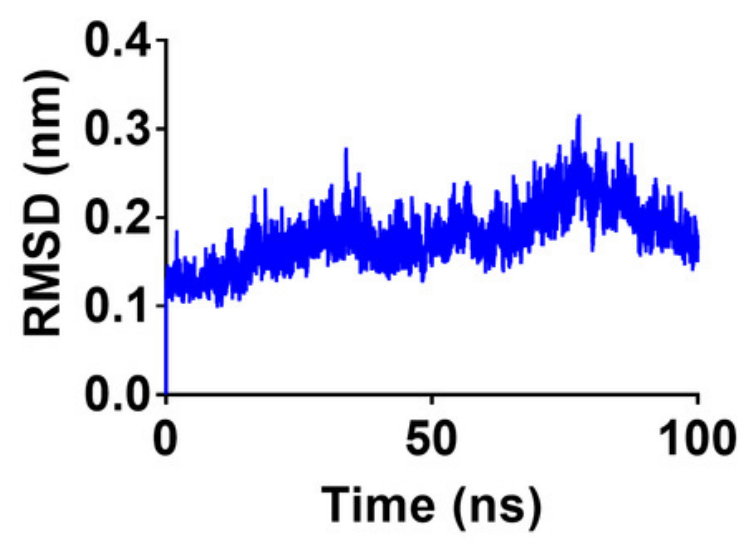

Atazanavir

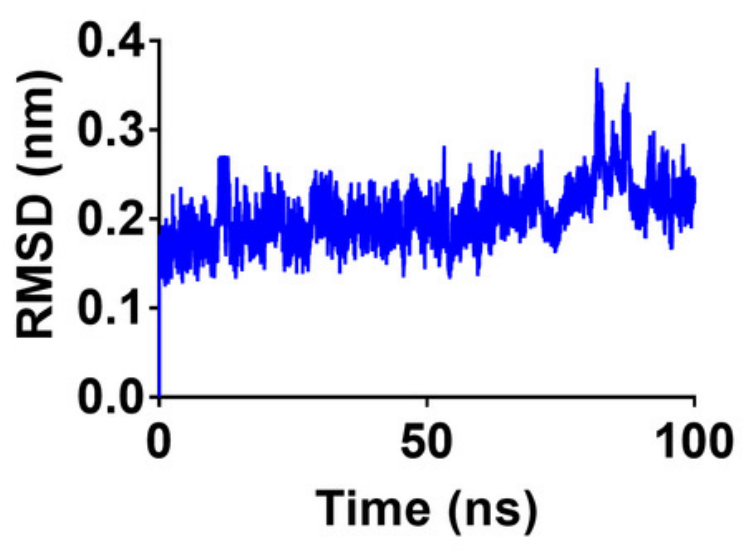

Birinapant

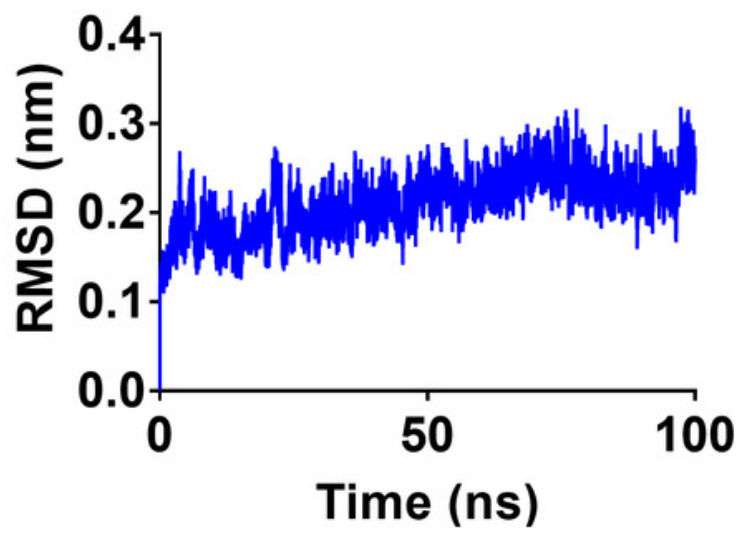

Alpha-Mangostin

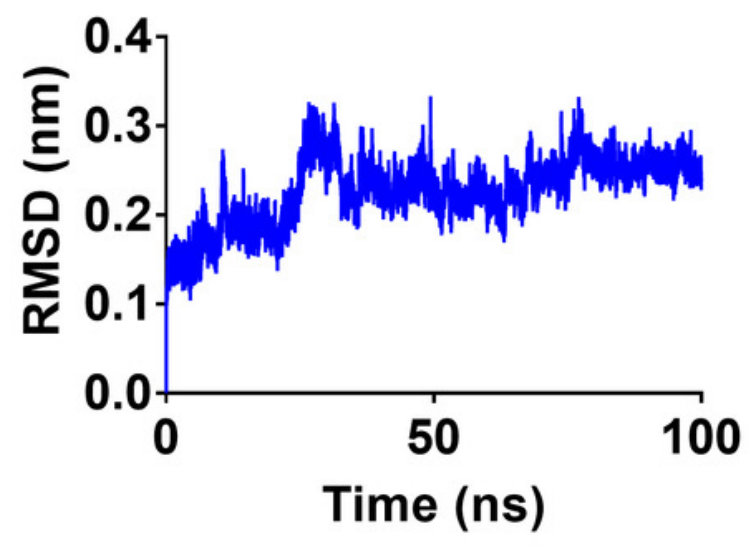


Figure 4

RMSF plot of the top four compounds after MDs for 100 ns.

- Alpha-Mangostin - Atazanavir - Birinapant - Lopinavir

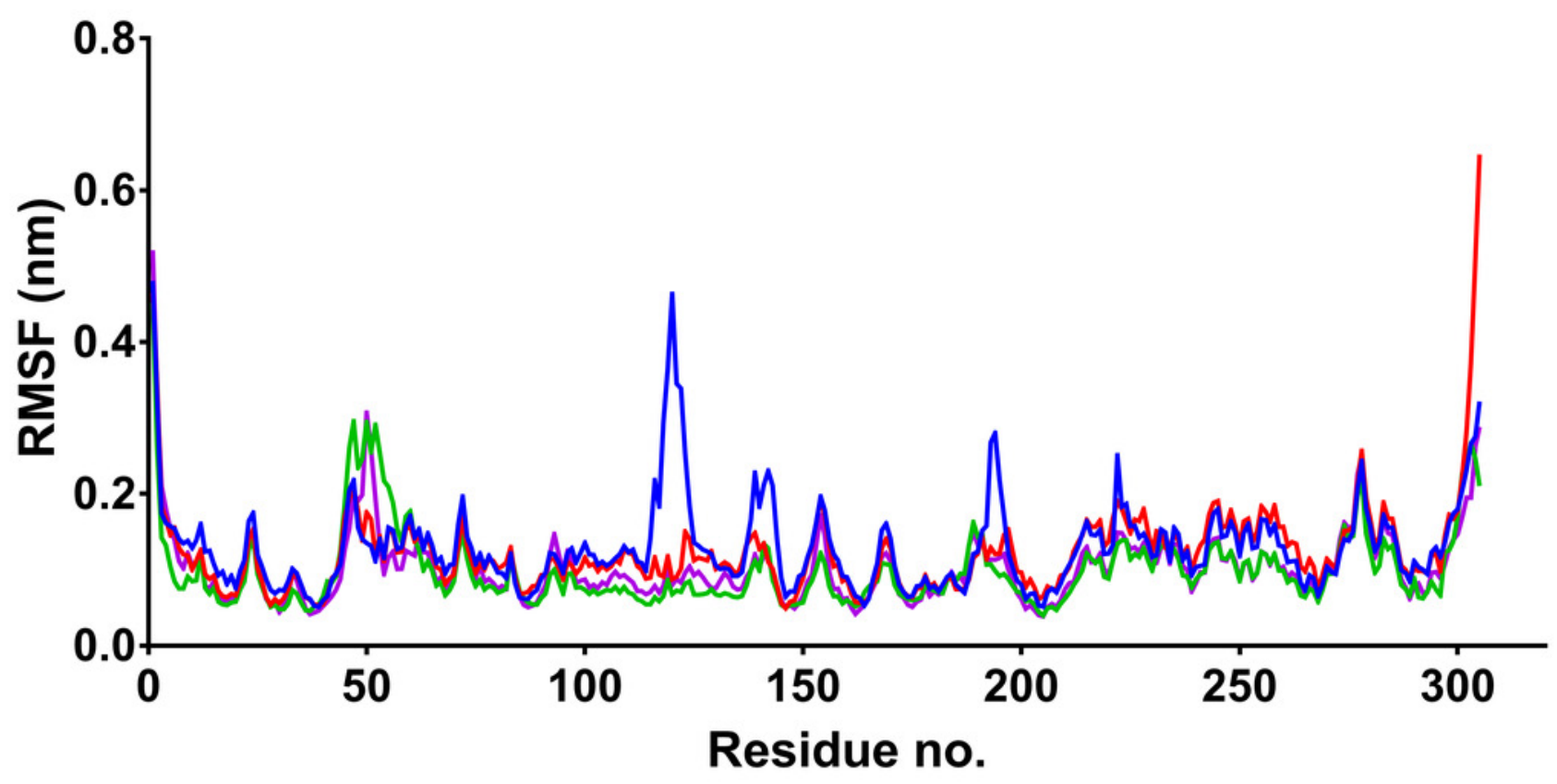


Figure 5

Radius of gyration of the top four compounds after MDs for 100 ns.
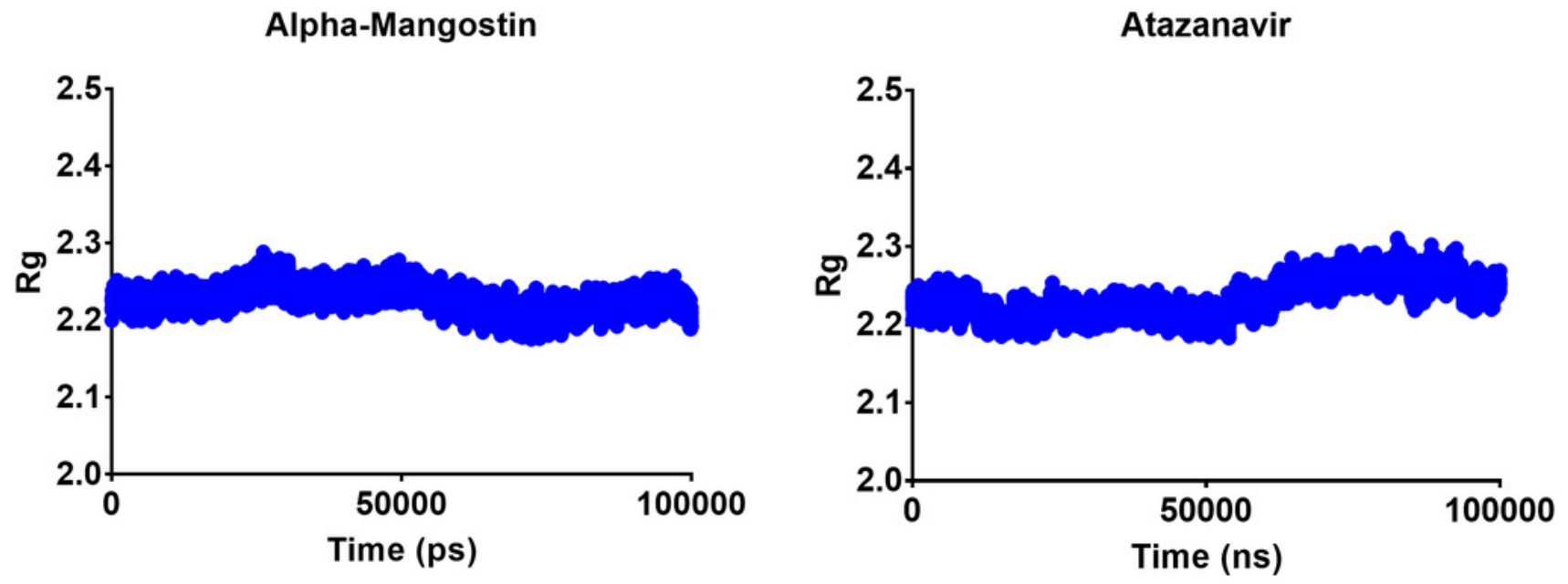

Birinapant

Lopinavir
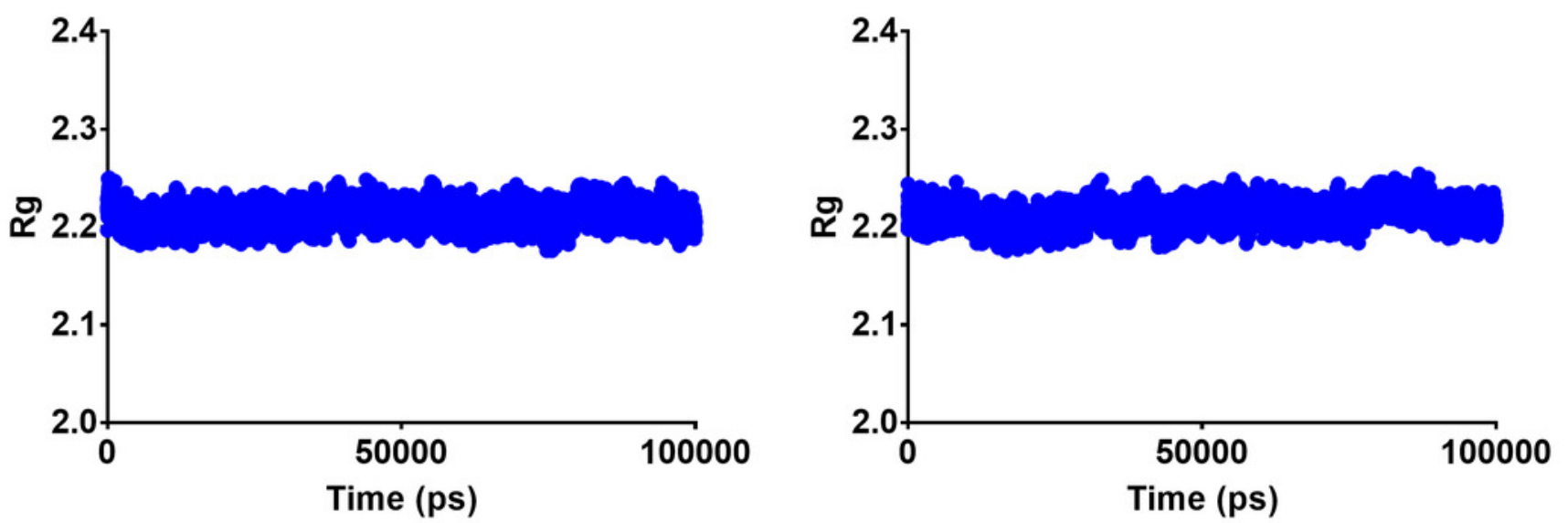


\section{Figure 6}

The hydrogen bond length of the top four compounds after MDs for $100 \mathrm{~ns}$.

- Alpha-Mangostin - Atazanavir - Birinapant - Lopinavir

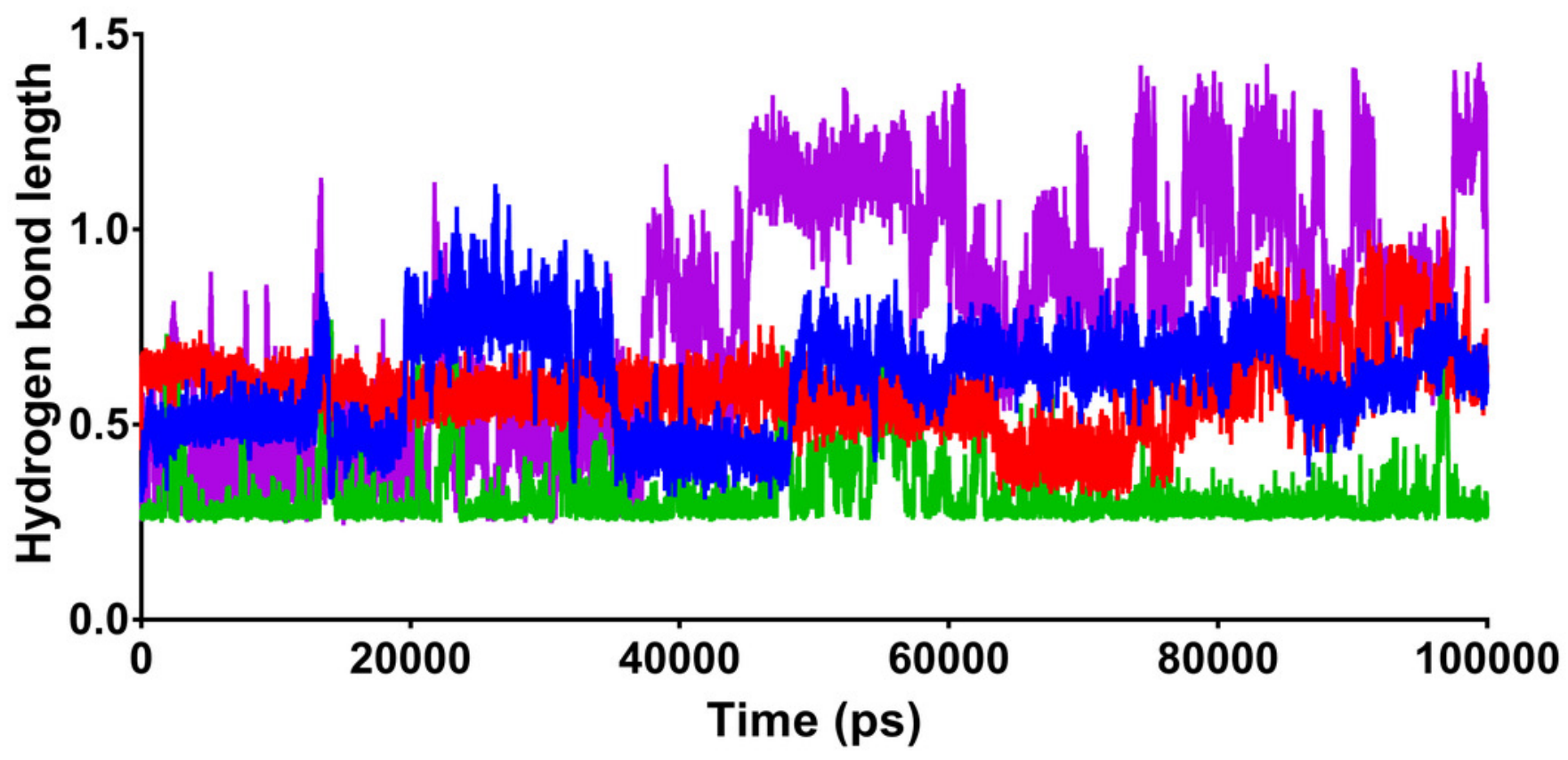




\section{Figure 7}

Effect of birinapant and atazanavir on the replication of SARS-CoV-2.

Vero E6 cells were infected with 0.1 MOI SARS-CoV-2 in 6-well plate and then treated with DMSO $(0.1 \%)$, birinapant $(10 \mathrm{mM})$ or atazanavir $(10 \mathrm{mM})$ at $3 \mathrm{~h}$ after virus infection $(\mathrm{n}=3)$. Supernatants of virus-infected cell cultures were collected at $48 \mathrm{~h}$ after virus infection. Virus replication in the supernatants was quantified by plaque formation assay. ${ }^{* *} p<0.01$.

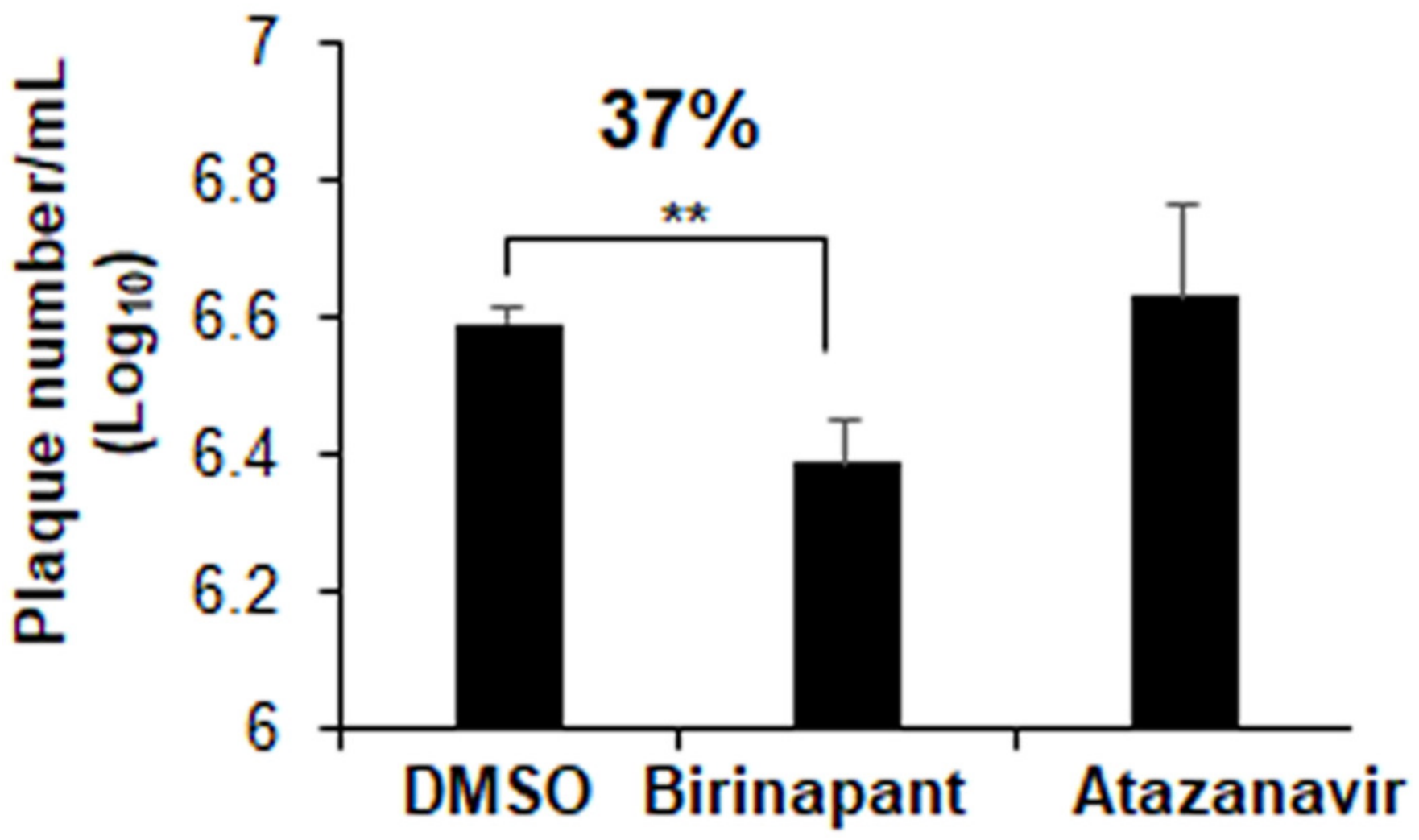




\section{Table 1 (on next page)}

The compounds dataset used in this study. 
1 Table 1. The compounds dataset used in this study.

\begin{tabular}{|c|c|c|c|}
\hline Library name & Company & $\begin{array}{l}\text { Number of } \\
\text { compounds }\end{array}$ & Method of selection \\
\hline $\begin{array}{l}\text { Main protease } \\
\text { targeted library }\end{array}$ & $\begin{array}{l}\text { Life chemicals } \\
\text { (Niagara-on- } \\
\text { the-Lake ON, } \\
\text { Canada) }\end{array}$ & 2300 & $\begin{array}{l}\text { Glide by Schrödinger, SP mode was used to } \\
\text { search Life chemicals HTS collection, by using } \\
\text { the main protease of SARS CoV-2 in complex } \\
\text { with an inhibitor N3. }\end{array}$ \\
\hline $\begin{array}{l}\text { Antiviral } \\
\text { Library by 2D } \\
\text { Similarity }\end{array}$ & Life chemicals & 19244 & $\begin{array}{l}\text { Antiviral Screening Compounds Library was } \\
\text { designed with } 2 \text { D fingerprint similarity search } \\
\text { against the } 41,514 \text { biologically active } \\
\text { compounds from therapeutically relevant viral } \\
\text { assays from different virus species. }\end{array}$ \\
\hline $\begin{array}{l}\text { Antiviral } \\
\text { Library by } \\
\text { Combined } \\
\text { Ligand-based } \\
\text { and Structure- } \\
\text { based } \\
\text { Approaches }\end{array}$ & Life chemicals & 3500 & $\begin{array}{l}\text { Antiviral protein targets were collected from } \\
\text { the RCSB PDB. The reference antivirals were } \\
\text { collected from ChEMBLdb and clustered } \\
\text { according to the target. The top compounds } \\
\text { were docked into the target protein and ranked. }\end{array}$ \\
\hline Antiviral library & $\begin{array}{l}\text { Asinex } \\
\text { (Winston- } \\
\text { Salem, NC } \\
\text { USA) }\end{array}$ & 6827 & $\begin{array}{l}\text { Small molecules and macrocycles with } \\
\text { antiviral activity. Specific designs include a- } \\
\text { helix mimetics, glycomimetic, diverse } \\
\text { synthetic macrocyles, and tri/tetra-substituted } \\
\text { scaffolds. }\end{array}$ \\
\hline $\begin{array}{l}\text { Enamine } \\
\text { antiviral library }\end{array}$ & $\begin{array}{l}\text { Enamine } \\
\text { (Monmouth } \\
\text { Jct., NJ, USA) }\end{array}$ & 4842 & $\begin{array}{l}\text { Nucleoside-like antiviral agents or Nucleoside } \\
\text { mimetics from screening collection. The } \\
\text { compounds contain natural-like moieties and } \\
\text { diverse heterocycles as bioisosters of } \\
\text { nucleosides. }\end{array}$ \\
\hline Antiviral & Selleck & 347 & Collection of antiviral compounds \\
\hline
\end{tabular}




\begin{tabular}{|l|l|l|l|}
\hline $\begin{array}{l}\text { compound } \\
\text { library }\end{array}$ & $\begin{array}{l}\text { (Houston, } \\
\text { Texas, United } \\
\text { States) }\end{array}$ & & \\
\hline \multicolumn{2}{|l|}{ Total no. of compounds } & 37060 & \\
\hline
\end{tabular}

2

3 
Table 2 (on next page)

Virtual screening and docking output of the top fourteen compounds. 
1 Table 2. Virtual screening and docking output of the top fourteen compounds.

\begin{tabular}{|c|c|c|c|c|c|c|c|c|}
\hline Title & $\begin{array}{c}\text { docking } \\
\text { score }\end{array}$ & $\begin{array}{c}\text { glide ligand } \\
\text { efficiency }\end{array}$ & $\begin{array}{c}\text { glide } \\
\text { lipo }\end{array}$ & $\begin{array}{c}\text { glide } \\
\text { hbond }\end{array}$ & $\begin{array}{c}\text { glide } \\
\text { evdw }\end{array}$ & $\begin{array}{c}\text { glide } \\
\text { ecoul }\end{array}$ & $\begin{array}{c}\text { glide } \\
\text { energy }\end{array}$ & $\begin{array}{c}\text { MMGBSA_d } \\
\text { G_Bind }\end{array}$ \\
\hline Rutin & -11.78 & -0.27 & -2.62 & -0.16 & -47.64 & -27.84 & -75.49 & -88.91 \\
\hline (-)-Epigallocatechin & -11.57 & -0.35 & -2.91 & -0.65 & -34.90 & -24.05 & -58.95 & -70.18 \\
\hline Sennoside A & -10.77 & -0.17 & -2.13 & -0.14 & -39.11 & -18.62 & -57.73 & -61.40 \\
\hline asinex8472 & -9.83 & -0.32 & -2.83 & -1.23 & -38.99 & -11.59 & -50.58 & -64.51 \\
\hline Atazanavir & -9.81 & -0.34 & -3.11 & -1.28 & -37.43 & -13.69 & -51.11 & -74.66 \\
\hline asinex8485 & -9.78 & -0.33 & -2.69 & -1.33 & -42.63 & -11.63 & -54.25 & -73.40 \\
\hline asinex6886 & -9.71 & -0.30 & -3.50 & -0.84 & -45.42 & -8.69 & -54.11 & -56.67 \\
\hline Alpha-Mangostin & -9.14 & -0.31 & -3.68 & -0.83 & -42.12 & -8.79 & -50.91 & -93.46 \\
\hline Glycitin & -8.83 & -0.28 & -2.96 & -0.32 & -32.44 & -15.39 & -47.83 & -77.38 \\
\hline Birinapant & -8.81 & -0.15 & -3.67 & -0.46 & -60.32 & -14.06 & -74.38 & -106.64 \\
\hline F2583-0433 & -8.80 & -0.29 & -2.97 & -1.20 & -42.87 & -17.08 & -59.95 & -89.30 \\
\hline F3234-0818 & -8.65 & -0.30 & -3.03 & -0.90 & -43.91 & -12.30 & -56.20 & -72.79 \\
\hline Lopinavir & -8.68 & -0.15 & -4.90 & -0.16 & -61.64 & -7.72 & -69.36 & -84.25 \\
\hline Cobicistat & -8.55 & -0.10 & -4.48 & -0.26 & -54.69 & -14.25 & -68.94 & -82.33 \\
\hline
\end{tabular}


Table 3(on next page)

Correlation statistics of the obtained docking score and the output parameters of XPdocking. 
1 Table 3. Correlation statistics of the obtained docking score and the output parameters of 2 XP-docking.

\begin{tabular}{|c|c|c|c|c|c|c|c|}
\hline & $\begin{array}{l}\text { docking } \\
\text { score } \\
\text { vs. } \\
\text { glide } \\
\text { ligand } \\
\text { efficiency }\end{array}$ & $\begin{array}{l}\text { docking } \\
\text { score } \\
\text { vs. } \\
\text { glide } \\
\text { lipo }\end{array}$ & $\begin{array}{l}\text { docking } \\
\text { score } \\
\text { vs. } \\
\text { glide } \\
\text { hbond }\end{array}$ & $\begin{array}{l}\text { docking } \\
\text { score } \\
\text { vs. } \\
\text { glide } \\
\text { evdw }\end{array}$ & $\begin{array}{l}\text { docking } \\
\text { score } \\
\text { vs. } \\
\text { glide } \\
\text { ecoul }\end{array}$ & $\begin{array}{l}\text { docking } \\
\text { score } \\
\text { vs. } \\
\text { glide } \\
\text { energy }\end{array}$ & $\begin{array}{c}\text { docking } \\
\text { score } \\
\text { vs. } \\
\text { MMGBS } \\
\text { A_dG_Bi } \\
\text { nd }\end{array}$ \\
\hline \multicolumn{8}{|l|}{ Pearson $r$} \\
\hline$r$ & 0.3446 & -0.6011 & -0.1216 & -0.3886 & 0.741 & 0.08881 & -0.3251 \\
\hline $\begin{array}{l}95 \% \\
\text { confidence } \\
\text { interval }\end{array}$ & $\begin{array}{r}-0.2275 \text { to } \\
0.7399\end{array}$ & $\begin{array}{r}-0.858 \\
\text { to }- \\
0.1035 \\
\end{array}$ & $\begin{array}{r}-0.6127 \\
\text { to } \\
0.4371 \\
\end{array}$ & $\begin{array}{r}-0.7621 \\
\text { to } \\
0.1788 \\
\end{array}$ & $\begin{array}{r}0.3468 \\
\text { to } \\
0.9127 \\
\end{array}$ & $\begin{array}{r}-0.4636 \\
\text { to } \\
0.5915 \\
\end{array}$ & $\begin{array}{r}-0.7298 \text { to } \\
0.2483\end{array}$ \\
\hline $\mathrm{R}$ squared & 0.1188 & 0.3613 & 0.0148 & 0.151 & 0.5491 & $\begin{array}{r}0.00788 \\
8 \\
\end{array}$ & 0.1057 \\
\hline \multicolumn{8}{|l|}{$\mathrm{P}$ value } \\
\hline $\begin{array}{l}\mathrm{P} \text { (two- } \\
\text { tailed) }\end{array}$ & 0.2275 & 0.0230 & 0.6787 & 0.1697 & 0.0024 & 0.7627 & 0.2567 \\
\hline $\begin{array}{l}\text { P value } \\
\text { summary }\end{array}$ & $\mathrm{ns}$ & * & ns & ns & $* *$ & ns & $\mathrm{ns}$ \\
\hline $\begin{array}{l}\text { Significant? } \\
(\text { alpha }= \\
0.05)\end{array}$ & No & Yes & No & No & Yes & No & No \\
\hline $\begin{array}{l}\text { Number of } \\
\text { XY Pairs }\end{array}$ & 14 & 14 & 14 & 14 & 14 & 14 & 14 \\
\hline
\end{tabular}

3 
Table 4 (on next page)

The MM-GBSA binding energy and the average structure RMSD of the top fourteen compounds after MDS for 20 ns. 
1 Table 4. The MM-GBSA binding energy and the average structure RMSD of the top fourteen 2 compounds after MDS for $20 \mathrm{~ns}$.

\begin{tabular}{|c|c|c|}
\hline Compound ID & binding energy $(\mathrm{kcal} / \mathrm{mol})$ & Average structure RMSD (nm) \\
\hline Birinapant & -139.154 & 0.171 \\
\hline Atazanavir & -130.299 & 0.180 \\
\hline Lopinavir & -114.654 & 0.138 \\
\hline Cobicistat & -111.296 & 0.214 \\
\hline Alpha-Mangostin & -107.446 & 0.151 \\
\hline 8472 & -102.564 & 0.151 \\
\hline (-)-Epigallocatechin gallate & -88.348 & 0.155 \\
\hline 3754 & -83.21 & 0.160 \\
\hline $3234-0818$ & -77.978 & 0.157 \\
\hline $2583-0433$ & -73.954 & 0.201 \\
\hline 8458 & -70.288 & 0.165 \\
\hline 6886 & -70.18 & 0.171 \\
\hline Rutin & -47.388 & 0.169 \\
\hline Glycitin & -42.627 & 0.175 \\
\hline Sennoside A & 59.744 & 0.138 \\
\hline & & \\
\hline & & \\
\hline
\end{tabular}

3

4 


\section{Table 5 (on next page)}

Decomposition of the estimated MMGBSA binding energy for the binding of alphamangostin, atazanavir, birinapant and lopinavir with SARS CoV-2 Mpro. 
1 Table 5. Decomposition of the estimated MMGBSA binding energy for the binding of alpha2 mangostin, atazanavir, birinapant and lopinavir with SARS CoV-2 Mpro.

\begin{tabular}{|l|r|r|r|r|}
\hline & \multicolumn{1}{|l|}{$\begin{array}{l}\text { Alpha- } \\
\text { Mangostin }\end{array}$} & Atazanavir & Birinapant & Lopinavir \\
\hline van der Waal energy & -184.419 & -292.82 & -134.625 & -227.389 \\
\hline Electrostattic energy & -28.745 & -81.919 & -305.47 & -40.001 \\
\hline Polar solvation energy & 113.399 & 287.534 & 335.31 & 177.784 \\
\hline SASA energy & -18.036 & -30.595 & -16.679 & -23.173 \\
\hline Binding energy & -117.863 & -117.827 & -121.346 & -112.801 \\
\hline
\end{tabular}

3

4

5 